\title{
QUANTITATIVE ESTIMATES OF TIME-AVERAGING IN MOLLUSK DEATH ASSEMBLAGES ON THE SOUTHERN BRAZILIAN SHELF UF/FLLRIIDA
}

\section{RITTER, Matias do Nascimento ${ }^{1,5}$, ERTHAL, Fernando ${ }^{2}$, KOSNIK, Matthew A. ${ }^{3}$, COIMBRA, João Carlos ${ }^{2}$, KAUFMAN, Darrell S. ${ }^{4}$, and KOWALEWSKI, Michał}

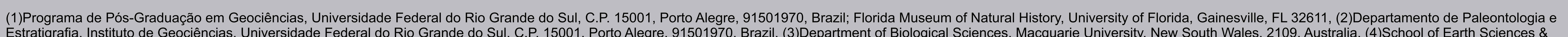

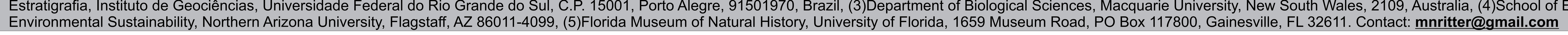

\section{INTRODUCTION}

Fossil assemblages are expected to be time-averaged due to temporal (and spatial) mixing of skeletal remains. Our quantitative understanding of time-averaging derives primarily from actualistic studies, in which direct numerical dating of individual specimens is used to assess the scale and structure of age mixing in surficial death assemblages (incipient fossil assemblages).

\section{MATERIAL AND METHODS}

Here, we examine time-averaging in shells collected from surficial sediments at three sites on a passive-margin subtropical shelf (the Southern Brazilian Shelf; $33^{\circ} \mathrm{S}$, Figure 1). Specimens of Mactra (Bivalvia: Mollusca) (Figure 2) were individually dated using amino acid racemization (AAR) $(n=60)$ calibrated against AMS radiocarbon ages $(n=15)$ (Figure 3$)$.



Figure 1 -Study area and sample sites on the inner
Southernmost Brazilian Shelf. Site $1: 7 \mathrm{~m}$; Site 2: $19 \mathrm{~m}$; Site

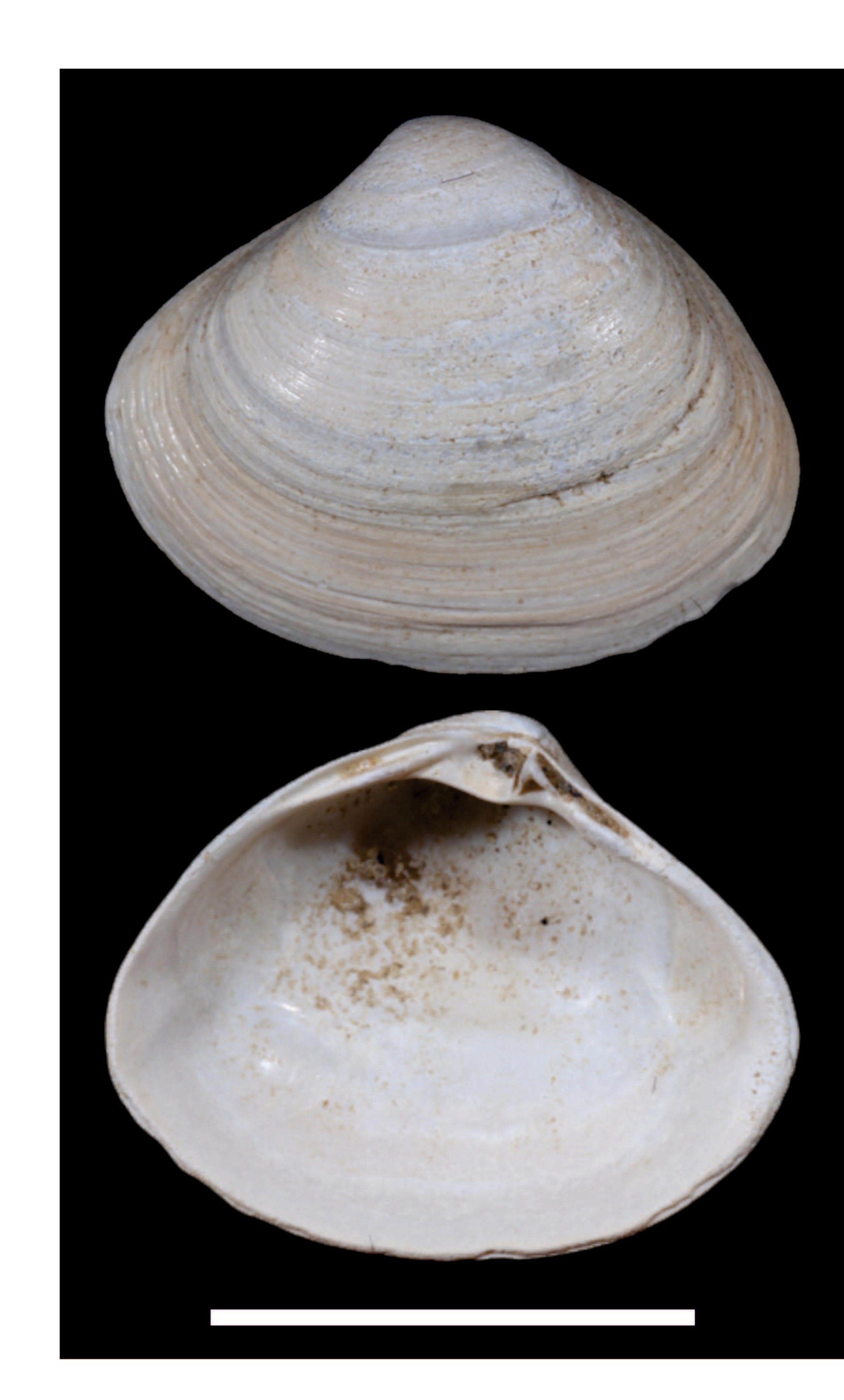

Figure $2-$ A right valve of Mactra sp
Scale bar: $10 \mathrm{~mm}$.

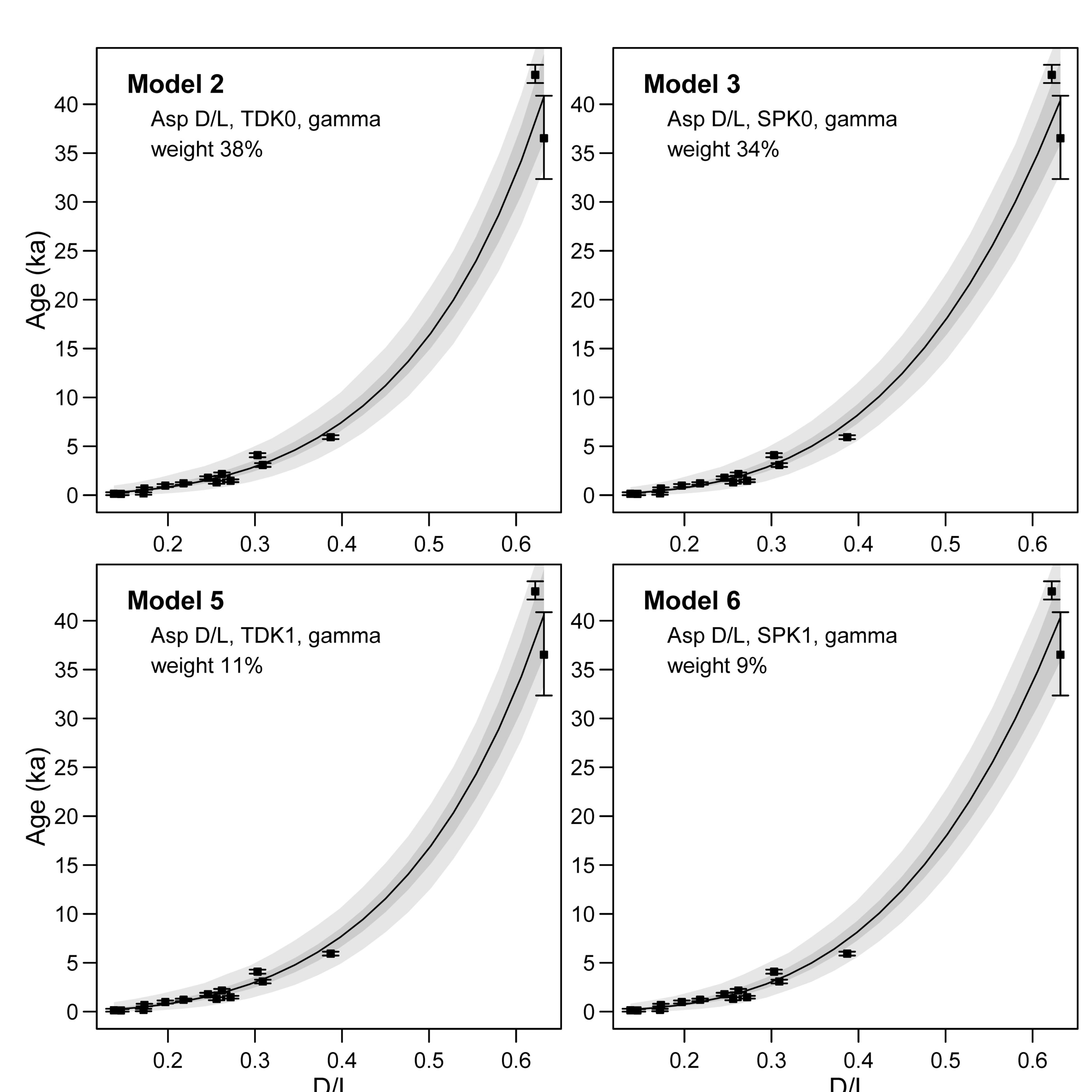
Figure 3 - The four best Asp-models and their respective
weights on the average gamma model. The dark shading
corresponds to the confidence interval for age, and light
The amount of time-averaging exceeding the expectation due to uncertainties in dating was determined by subtracting the age-estimation error from the total age-estimate variability, based on 10,000 Bayesian Markov-chain Monte-Carlo replicates.

\section{RESULTS}

The ${ }^{14} \mathrm{C}$-calibrated AAR ages, pooled across all three sites, indicate that individual mollusk shells vary in age from 0 to $\sim 56$ cal kyr BP. The age distribution is right skewed (i.e., dominated by young specimens) (Figure 4) suggesting that the sampled death assemblages is time averaged over multi-millennial time scales.

The magnitude of time-averaging varied inversely with the water depth, from $<15 \mathrm{yr}$ in the deepest site (21 meters) up to 1020-1250 yr in the shallowest site (7 meters) (Table 1$)$.

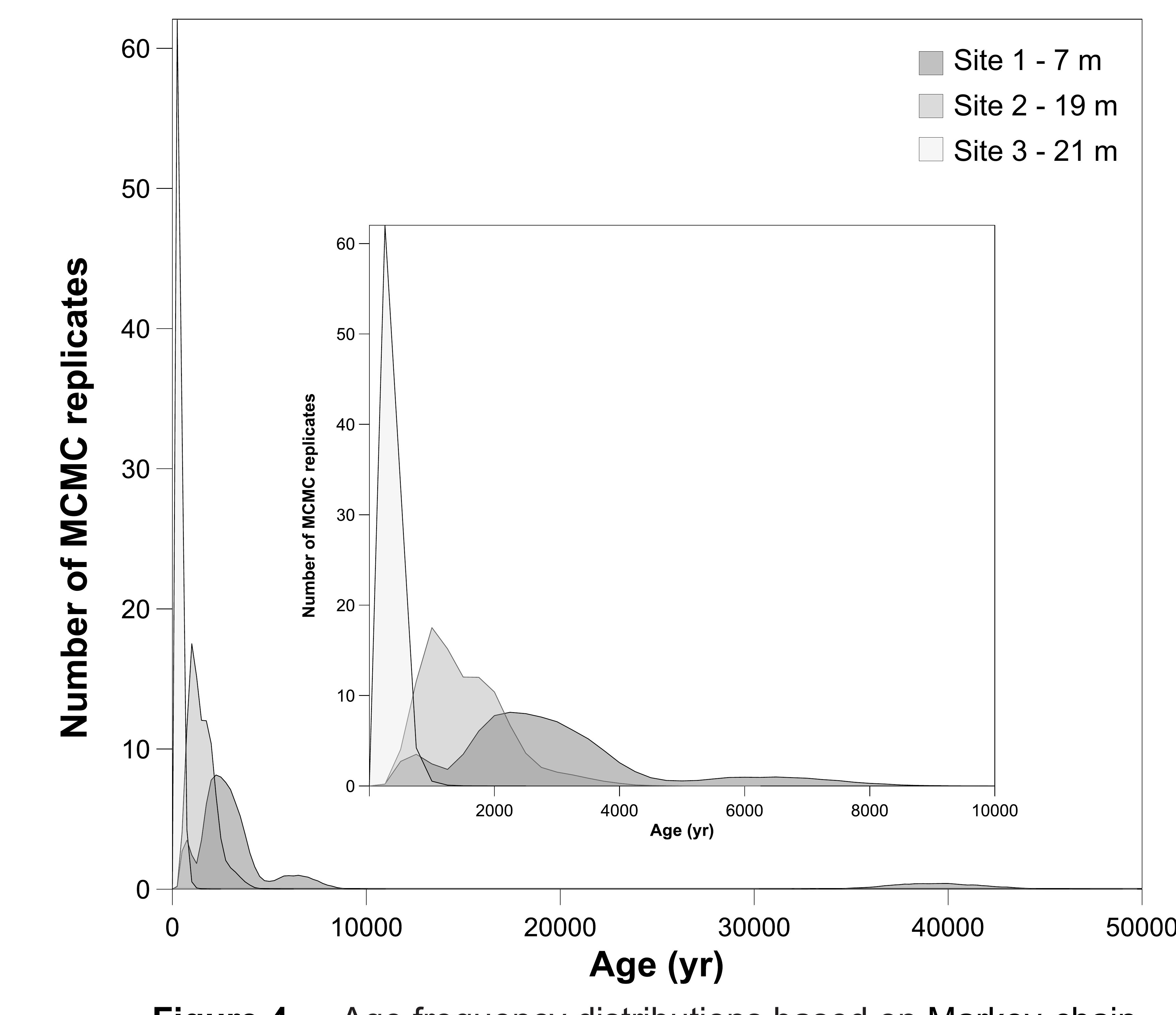

Figure 4 -Age frequency distrn
Monte-Carlo replicates by site.

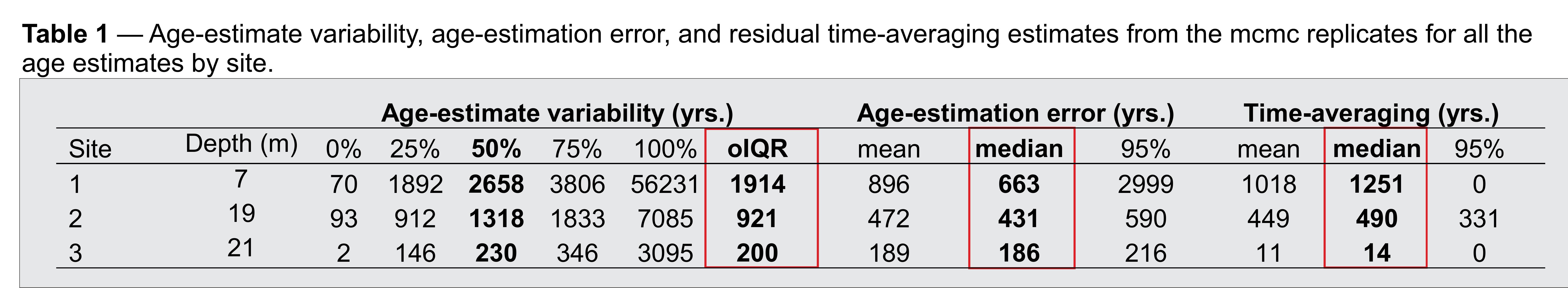

\section{DISCUSSION AND CONCLUSIONS}

The multi-millennial scale of time-averaging observed for pooled data and strongly rightskewed nature of age distributions are consistent with other studies of time-averaging in sediment-starved shelf settings. The substantial temporal span of dated specimens points to their potential value as archives of the paleoenvironmental history of the Southern Brazilian shelf over the most recent millennia. 